\title{
CLINICAL OUTCOME MEASURES OF PSORIASIS
}

\author{
C. BONIFATI, E. BERARDESCA \\ Dept. of Clinical Dermatology, San Gallicano Dermatological Institute, Rome, Italy
}

\begin{abstract}
SUMMARY
Several tools have been introduced in clinical trials to quantify the severity and the response to a given therapeutic regimen of both psoriasis and psoriatic arthritis. Each method present specific advantages and limitations. Here we will discuss some of the most popular clinical outcome measures of both psoriasis (Psoriasis Severity Index, Physician Global Assessment, National Psoriasis Fundation-Psoriasis Score, Dermatology Life Quality Index) and psoriatic arthritis (American College Rheumatology response criteria, Psoriatic Arthritis Response Criteria).
\end{abstract}

Key words: Psoriasis, psoriatic arthritis, outcome

\section{INTRODUCTION}

Psoriasis and psoriatic arthritis (PsA) are common conditions that have a significant impact on affected patients. The availability of novel and expensive therapeutic agents for both psoriasis and PsA, such as "biologics", has generated considerable interest in clinical trials.

Therefore, there is a great need for standardized outcome measures to evaluate the activity of the diseases mentioned above as well as their response to therapy. To date, different tools have been developed for such purposes, the most popular ones will be analyzed below.

\section{PSORIASIS ASSESSMENT TOOLS}

The Psoriasis Area Severity Index (PASI) (1) is currently the most popular tool in clinical studies. It is a measure of the average redness, thickness, and scaliness of the lesions (each graded on a 0-4 scale), weighed by the area of involvement (Tab. I). The final result of this method of assessment ranges from 0.0 to 72.0 .

In most clinical trials a $\geq 75 \%$ reduction from baseline PASI scores (PASI 75) is the benchmark of primary endpoints in assessing therapies for

Corresponding author:

Enzo Berardesca, MD

San Gallicano Dermatological Institute

Via Chianesi 53 - 00144 Rome, Italy

E-mail: berardesca@ifo.it psoriasis (2). However, PASI 75 has been considered too stringent by Carlin CS and coworkers (3). In fact, these authors published data indicating that a PASI reduction $\geq 50$ (PASI 50) demonstrates a clinically meaningful improvement and represents an appropriate primary endpoint for clinical trials. The main limitations of the PASI score are:

1) no discrimination when low body surface areas of involvement are present;

2) upper end of scale is only theoric (2).

The Physician Global Assessment (PGA) (4) is another widely used system employed in psoriasis clinical trials. In its typical formulation, it is a 7point scale ranging from clear to severe (Tab. II). In most versions of the PGA, the individual elements of psoriasis plaque morphology or degree of body surface area involvement are not quantified. Although PGA has the advantage to evaluate disease severity in a more intuitive way than the 0 to 72 score of PASI, it presents different limitations, for example:

1) various PGAs have been utilized with different descriptions and scores making it more difficult to compare data among different clinical trials;

2 ) it does not discriminate small changes;

3) range not robust (2).

The National Psoriasis Fundation- Psoriasis Score (NPF-PS) (5) is a responder index that encompasses different subdomains:

1) induration at two target sites;

2) current and baseline body surface area; 
Table I - Elements of the Psoriasis Area and Severity Index (PASI).

\begin{tabular}{|c|c|c|}
\hline & Upper extremities & Lower extremities \\
\hline $\begin{array}{l}1 \text { Redness+ } \\
2 \text { Thickness }+ \\
3 \text { Scale+ } \\
4 \text { Sum of rows } 1,2 \text {, and } 3 \\
5 \text { Area score } \neq \\
6 \text { Score of row } 4 \times \text { row } 5 \times \text { the area multiplier } \\
7 \text { Sum row } 6 \text { for each column for PASI score }\end{array}$ & row $4 \times$ row $5 \times 0.1$ row $4 \times$ row $5 \times 0,2$ & row $4 \times$ row $5 \times 0,3$ row $4 \times$ row $5 \times 0,4$ \\
\hline 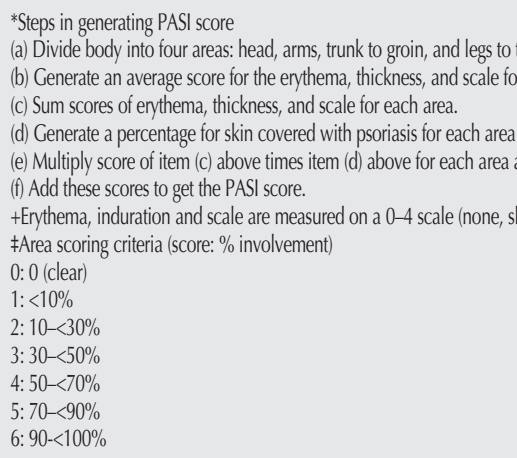 & $\begin{array}{l}\text { of buttocks. } \\
\text { ch of the } 4 \text { areas }(0=\text { clear; } 1-4=\text { increasing severity })+\text {. } \\
\text { d convert that to a } 0-6 \text { scale }(0=0 \% ; 1=<10 \% ; 2=10-<30 \% ; 3 \\
\text { multiply that by } 0.1,0.2,0.3 \text {, and } 0.4 \text { for head, arms, trunk, and } \\
\text { t, mild, moderate, severe) }\end{array}$ & $\begin{array}{l}=30-<50 \% ; 4=50-<70 \% ; 5=70-<90 \% ; 6=90-100 \% \text {. } \\
\text { legs, respectively. }\end{array}$ \\
\hline
\end{tabular}

Table II - Description of a Physician Global Assessment (PGA).

$\begin{array}{ll}\text { Sever } & \text { Very marked plaque elevation, scaling, and/or erythema } \\ \text { Moderate to Severe } & \text { Marked plaque elevation, scaling, and/or erythema } \\ \text { Moderate } & \text { Moderate plaque elevation, scaling, and/or erythema } \\ \text { Mild to moderate } & \text { Intermediate between moderate and mild } \\ \text { Mild } & \text { Slight plaque elevation, scaling, and/or erythema } \\ \text { Almost clear } & \text { Intermediate between mild and clear } \\ \text { Clear } & \text { No signs of psoriasis (postinflammatory hyperpigmentation may be present) }\end{array}$

Tabella III - Elements of National Psoriasis Foundation Psoriasis Score (NPF-PS).

\begin{tabular}{|lc|}
\hline & Score \\
\hline Induration of representative target lesion A $(0-1.25 \mathrm{~mm})$ & $0-5$ \\
Induration of representative target lesion B (0-1.25 mm) & $0-5$ \\
Body surface area relative to baseline as \% (score is $20 \%$ intervals) & $0-5$ \\
Physician global assessment (static and defined) & $0-5$ \\
Patient global assessment (relative to worst disease has ever been) & $0-5$ \\
Patient assessment of itch (defined score = average over 24 hours) & $0-5$ \\
\hline
\end{tabular}

3) physician global assessment;

4) patient global assessment;

5) patient assessment of itch (Tab. III).

To help improve intra-rater and inter-rater reliability of the induration score, the NPF-PS utilizes a reference card embossed with elevations that increase at $0.25 \mathrm{~mm}$ intervals.

This composite index presents a number of advantages such as:
1) correlation with Dermatology Life Quality Index;

2) a good discrimination when body surface area is low;

3) patient input is considered;

4) thickness is predominate component;

5) all elements are defined. However, the NPF-PS is time consuming, has not been widely tested and has not yet been accepted by approving agencies nor clinicians. 
The Dermatology Life Quality Index (DLQI) (6) is the most widely used measure for assessing quality of life related to skin disease in psoriasis trials (2). This tool consists of 10 questions covering six domains (symptoms and feelings, daily activities, leisure, work and school, personal relationships, and trouble with psoriasis treatment).

The response options range from 0 , not affected at all, to 3 , very much affected.

This gives an overall range of $0-30$ where lower scores mean better quality of life. The reliability, construct validity, and sensitivity to change of the DLQI have all been demonstrated in psoriasis patients (7).

\section{PSA ASSESSMENT TOOLS}

The American College Rheumatology (ACR) response criteria, initially developed for Reumatoid Arthritis clinical trials (8), is an outcome measure of PsA, which requires improvement in:

1) tender joint count;

2) swollen joint count;

3) 3 of 5 additional measures, which include patient global assessment of disease activity, physician global assessment of disease activity, patient assessment of pain, functional status (e.g. using the Healt Assessment Questionnare, 9) and an acute phase reactant.

The original criteria, commonly called the ACR 20 (Tab. IV), require 20\% improvement in these measures (8); a more extensive improvement may be documented according to ACR50 and ACR70, which require $50 \%$ and $70 \%$ improvement, respectively. ACR20 criteria are reported to be as effective as higher levels to distinguish active treatment from placebo responses (10), and have been widely used as a primary outcome measure in clinical trials in PsA with good performance (11).

Psoriatic Arthritis Response Criteria (PsARC) is a tool specifically developed for a study to evaluate the efficacy of sulfasalazine in PsA (12). Th e PsARC is composed of four measures, including:

1) patient global assessment of disease activity (improvement of 1 on a 5 point Likert scale is required for a response;

2) physician global assessment of disease activity (improvement of 1 on a 5 point Likert scale is required for a response);

3) joint pain (reduction of $30 \%$ or more in total score, assessing either 68 or 78 joints, requiring a 4 point scale for a response), and iv) joint swelling (reduction of $30 \%$ or more in total score, assessing either 66 or 76 joints, requiring a 4 point scoring scale for a response) (Tab. V).

In order to be a 'PsARC responder', patients must achieve improvement in 2 of 4 measures, one of which must be joint pain or swelling, without worsening in any measure. In several trials of various therapeutic agents where it was

Table IV - ACR 20.

Patients must show 20\% improvement in:

Tender and swollen joint counts and 3 of 5 of other measures:

- Patient global assessment

- Physician global assesment

- Patient pain assessment

- Physical disability score

- Serum levels of acute phase reactants

Table V - PsARC.

Patients must show improvement in 2 of 4 criteria, including:

and

- Physician global assessment (0-5)

- Patient global assessment (0-5)

- Tender joint score $(>30 \%)$

- Swollen joint score (>30\%)

- Improvement in at least 1 of 2 joint scores

- No worsening in any criteria 
included as a primary or secondary outcome measure, the PsARC has been shown to be able to distinguish active treatment from placebo responses $(11,13)$.

\section{REFERENCES}

1. Fredriksson T, Pettersson U. Severe psoriasis-oral therapy with a new retinoid. Dermatologica 1978; 157: 23844.

2. Feldman SR, Krueger GG. Psoriasis assessment tools in clinical trials. Ann Rheum Dis 2005; 64 (Suppl II): ii65-8.

3. Carlin CS, Feldman SR, Krueger JG, Menter A, Krueger GG. A 50\% reduction in the Psoriasis Area and Severity Score (PASI 50) is a clinically significant endpoint in the assessment of psoriasis. J Am Acad Dermatol 2004; 50: 859-66.

4. Langley RG, Ellis CN. Evaluating psoriasis with Psoriasis Area and Severity Index, Psoriasis Global Assessment, and Lattice System Physician's Global Assessment. J Am Acad Dermatol 2004; 51: 563-9.

5. Gottlieb AB, Chaudhari U, Baker DG, Perate M, Dooley LT. The National Psoriasis Foundation Psoriasis Score (NPF-PS) system versus the Psoriasis Area Severity Index (PASI) and Physician's Global Assessment (PGA): a comparison. J Drugs Dermatol 2003; 2: 260-6.
6. Finlay AY, Khan GK. Dermatology Life Quality Index (DLQI) - a simple practical measure for routine clinical use. Clin Exp Dermatol 1994; 19: 210-16.

7. Ashcroft DM, Li Wan Po A, Williams HC, Griffiths CE. Quality of life measures in psoriasis: a critical appraisal of their quality. J Clin Pharm Ther 1998; 23: 391-8.

8. Felson D, Anderson J, Boers M et al. American College of Rheumatology preliminary definition of improvement in rheumatoid arthritis. Arthritis Rheum 1995; 38 : 727-35.

9. Fries J, Spitz P, Kraines R et al. Measurement of patient outcomes in arthritis. Arthritis Rheum 1980; 23: 137-45.

10. Felson D, Anderson J, Lange M, Wells G, La Valley M. Should improvement in rheumatoid arthritis clinical trials be defined as fifty percent or seventy percent improvement in core set measures, rather then twenty percent? Arthritis Rheum 1998; 41: 1564-70.

11. Taylor WJ. Assessment of outcome in psoriatic arthritis. Curr Opin Rheumatol 2004; 16: 350-6.

12. Clegg D, Reda D, Mejias E et al. Comparison of sulfasalazine and placebo in the treatment of psoriatic arthritis: a department of Veterans Affairs cooperative study. Arthritis Rheum 1996; 39: 2013-20.

13. Gladman D, Helliwell P, Mease P, Nash P, Ritchling C, Taylor W. Assesment of patients with psoriatic arthritis: a review of currently available measures. Arthritis Rheum 2004; 50: 24-35. 